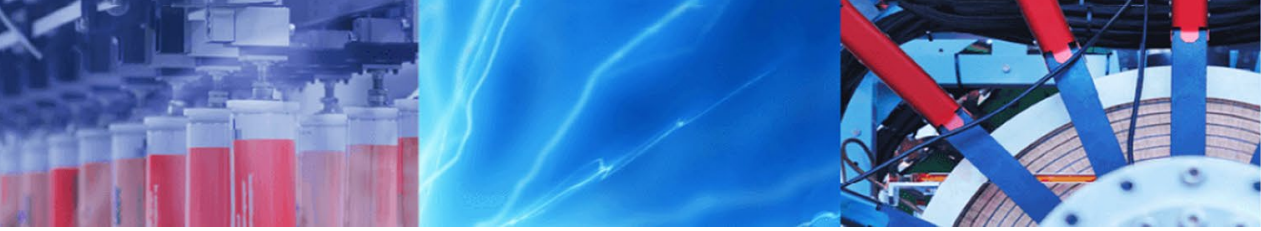

Research Article

\title{
A density functional theory (DFT) study of the doping effect on 4-[2-(2-N, N-dihydroxy amino thiophene) vinyl] benzenamine
}

\author{
Côme Damien Désiré Mveme ${ }^{1}$. Fridolin Tchangnwa Nya ${ }^{1}$ · $\cdot$ Geh Wilson Ejuh ${ }^{2,3}$. Jean Marie Bienvenu Ndjaka ${ }^{4}$
}

Received: 25 May 2020 / Accepted: 27 January 2021 / Published online: 12 February 2021

(c) The Author(s) 2021 OPEN

\begin{abstract}
In the present work, density functional theory was used at the B3LYP, CAM-B3LYP and B3PW91 levels with the 6-311++G $(d, p)$ basis set, in other to study the structural, optoelectronic, nonlinear optical, piezoelectric and thermodynamic properties of 4-[2-(2-N, N-dihydroxy amino thiophene) vinyl] benzenamine (DATVB) molecule doped with chlorine and fluorine respectively. The results obtained show that doping significantly improves the properties of this material. The materials obtained after doping 4-[2-(2-(5-(bis (chlorooxy) amino) thiophene) vinyl] benzenamine (BCATVB) and 4-[2-(2(5-(bis (fluorooxy) amino) thiophene) vinyl] benzenamine (BFATVB) are good semiconductors because their gap energy is range between 1 and $1.5 \mathrm{eV}$ which is less than $3 \mathrm{ev}$. Their first order hyperpolarizabilities $\left(\beta_{\text {mol }}\right)$ are very high compared to para-nitroaniline ( $p-N A)$ known as reference molecule for nonlinear optical properties. The obtained results predisposes them as good nonlinear optical materials with applications in photonics, optical signal processing devices, dynamic imaging, data storage and computer devices. The piezoelectric and pyroelectric coefficients of the fluorinated molecule are higher than those of the reference organic molecule polyvinylidene fluoride. This led us to the conclusion that, these molecules can also be used for applications in piezoelectricity.
\end{abstract}

Keywords DFT · Optoelectronics · Nonlinear optical properties · Piezoelectricity · Thermodynamics · Doping

\section{Introduction}

Our time is marked by the search for new substitute materials that meet very specific needs. In this context, materials base organic molecules have many advantages: they are most often light, transparent or colored on demand, easy to use, durable, easy to synthesize, have an ultra-fast optical response and great flexibility [1-6]. These organic molecules having all these characteristics are assimilated to organic semiconductors. Organic semiconductors have been studied intensively in recent years, due to their unique optical properties, such as: size-dependent emission wavelength, narrow emission spectrum, and high luminescent efficiency [7-9]. All of these attractive characteristics make organic semiconductor excellent candidates for the next-generation lighting and display, as well as optical communication technologies. Organic materials have a very low conductivity as long as they are intrinsic, therefore having the possibility of a controllable doping technology is even more desirable. Different excitations or doping can generate charges or excited states in semiconductors. We cite a few, electronic doping by charge transfer or chemical doping: it consists in doping the semiconductor, that is to say increasing the density of charge carriers (electrons and holes), by adding donor species ( $n$-type doping) or acceptors ( $p$-type doping) of

$\triangle$ Fridolin Tchangnwa Nya, nyafridolin@yahoo.fr | ${ }^{1}$ Materials Science Laboratory, Department of Physics, Faculty of Science, University of Maroua, P.O. Box 814, Maroua, Cameroon. ${ }^{2}$ Department of Electrical and Electronic Engineering, National Higher Polytechnic Institute, University of Bamenda, P. O. Box 39, Bambili, Cameroon. ' ${ }^{3}$ Department of General and Scientific Studies, University of Dschang, P.O. Box 134, IUT-FV Bandjoun Bandjoun, Cameroon. ${ }^{4}$ Department of Physics, Faculty of Science, University of Yaoundé I, P.O. Box 812, Yaounde, Cameroun. 
electrons [10], doping by field effect or injection (which locally modifies the concentration of carriers): in the case of metal-semiconductor molecule contact, the charges can be injected directly from the metal to the semiconductor under the application of a voltage. This principle is used in transistors and light emitting diodes [11]. Upon doping, the charge carrier density can be significantly increased resulting in a good conductivity, ohmic injection at the contacts, and a negligible drop of voltage across these layers. Obviously, this concept is allow for new device structures, like pn-junctions, that are known from inorganic semiconductors and can be applied to the field of organic devices as well. These doping, considerably improve the optoelectronic and nonlinear optical properties of these organic compounds. Significant interest still exists in the design and development of materials exhibiting an important second order NLO response due to potential application in telecommunications, optical computing, and optical signal processing [12]. In fact, the third order response governed by the second hyperpolarizability offers a more varied and richer behavior than the second order NLO process due to the higher dimensionality of the frequency space. Recently, one can observe a huge increase in the NLO properties of conjugated and organics functionalized molecules due to their potential applications in optoelectronic devices [13, 14]. The same, materials with suitable nonlinear responses to incident light can be exploited to alter propagation characteristics such as frequency, amplitude or phase of the transmitted electromagnetic radiation [15]. A study of the optoelectronic, nonlinear optical and thermodynamic properties of the 4- [2- (2-N, N-dihydroxy amino thiophene) vinyl] benzenamine (DATVB) (See Fig. 1) molecule was carried out by F. Tchangnwa Nya et al. [16]. The results obtained show that this molecule has a gap energy $\mathrm{E}_{\text {gap }}=2.16 \mathrm{eV}$, a dipole moment $\mu=2.88$ Debye and a first order hyperpolarisability $\beta_{\text {mol }} \cdot 10^{-33}=412.27$ esu which predisposes it for applications in electronics, optoelectronics and non-linear optics [16]. In order to design such high performance NLO materials, various strategies have been put forth for both organic and inorganic systems. For organic systems, NLO response is generally enhanced by increasing the degree of charge transfer [17]. In this manuscript, we report the

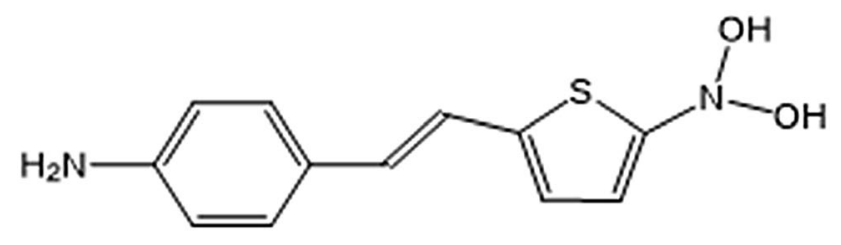

Fig. 1 4-[2-(2-N, N-dihydroxy amino thiophene) vinyl] benzenamine (DATVB) molecule

SN Applied Sciences

A SPRINGER NATURE journal halogen (chlorine and fluorine) doping of DATVB for designing novel materials more active for electronic and photonic devices and suggest an others fields of applications. The structural, electronic, optoelectronic and nonlinear optical properties of the doped molecules i.e. 4-[2-(2(5-(bis (chlorooxy) amino) thiophene) vinyl] benzenamine (BCATVB) and 4-[2-(2-(5-(bis (fluorooxy) amino) thiophene) vinyl] benzenamine (BFATVB) are also studied theoretically. The enhancement in the NLO properties of BCATVB and BFATVB is investigated through first and second hyperpolarizability calculations. The results of doped structures (BCATVB and BFATVB) are also compared with each other to study the doping effect of DATVB. This investigations is carried out using the quantum method approach, in particular the density functional theory (DFT).

\section{Computational methodology and theoretical frame work}

\subsection{Computational methodology}

In this study, the geometrical and electronic properties of all systems in their ground state are studied by density functional theory (DFT) using B3LYP and B3PW9 exchange-correlation functional combined with $6-311 \mathrm{G}++(\mathrm{d}, \mathrm{p})$ basis set for all atoms to predict the optimized structures, optical properties, and the quantum chemical properties of all studied compounds. The DFT method has proven to be one of the most accurate methods for the computation of the electronic structure of solids $[15,18,19]$. The geometries were optimized by minimizing the energies with respect to all geometrical parameters without imposing any molecular symmetry constraints. Gauss View 6.0.16 [20] has been used to draw the structures of the optimized geometries. Also, frequency calculations were performed using the same level of theory. The B3LYP and B3PW91 has been chosen for our calculation in ground state for its performance to describe the optoelectronics properties for organic materials containing especially $\mathrm{C}, \mathrm{H}, \mathrm{S}$ and halogen atoms[21-24]. These two methods have been chosen for comparison purpose and also because no theoretical and experimental study have been done on these doped molecules. Besides B3LYP and B3PW91, calculations of dipole moment, polarizability and hyperpolarizability are also perform using CAM-B3LYP with the same basis set. This functional is quite reliable for excitation by charge transfer, non-covalent interactions [25-29]. The localization of electron populations has been obtained through the calculated electronic populations of the HOMO (Highest Occupied Molecular Orbital) and LUMO (Lowest Unoccupied Molecular Orbital) with their 
energy. All calculations have been performed by Gaussian 09 package [30].

\subsection{Theoretical frame work}

The mathematical relations used to calculate the optoelectronic, nonlinear optical, electronic transport and chemical parameters are as follows:

For optoelectronic properties, the electric displacement field is given by

$D=\varepsilon_{0} E+P=\varepsilon_{0} \varepsilon_{r} E=\varepsilon_{0}\left(1+\chi_{e}\right) E$

where

$P=\varepsilon_{0} \chi_{e} E=\left(\varepsilon_{r}-1\right) E \varepsilon_{0}$

is the density of polarization.

The refractive index is given by the relation:

$n=\sqrt{1+\chi_{e}}$

In the non-linear domain, the dipole moment is governed by the formula: where

$\mu=\alpha E+\beta E^{2}+\gamma E^{3}+\cdots$

$\beta=\left[\left(\beta_{x x x}+\beta_{x y y}+\beta_{x z z}\right)^{2}+\left(\beta_{y y y}+\beta_{y x x}+\beta_{y z z}\right)^{2}+\left(\beta_{z z z}+\beta_{z x x}+\beta_{z y y}\right)^{2}\right]^{1 / 2}$

and

$\gamma=(1 / 5)\left[\gamma_{x x x x}+\gamma_{y y y y}+\gamma_{z z z z}+2\left(\gamma_{x x y y}+\gamma_{x x z z}+\gamma_{y y z z}\right)\right]$

are respectively the first and the second hyperpolarisability.

The anisotropy, $\Delta \alpha$ are calculated by

$\Delta \alpha=\frac{1}{2}\left[\left(\alpha_{x x}-\alpha_{y y}\right)^{2}+\left(\alpha_{y y}-\alpha_{z z}\right)^{2}+\left(\alpha_{z z}-\alpha_{x x}\right)^{2}+6\left(\alpha_{x y}^{2}+\alpha_{y z}^{2}+\alpha_{z x}^{2}\right)\right]^{1 / 2}$

In the linear domain, $\beta \approx 0, \gamma \approx 0$, the dipole moment will be given by the formula

$\mu=\alpha E$

We show that:

$\alpha=\frac{1}{3}\left(\alpha_{x x}+\alpha_{y y}+\alpha_{z z}\right)$

$\mu=\sqrt{\mu_{x}^{2}+\mu_{y}^{2}+\mu_{z}^{2}}$

These relations above are also found in the literature $[15,16,31-35]$.

For electronic transport and quantum chemical properties: parameters such as energy gap $\left(E_{\text {gap }}\right)$, ionization potential (IP), electron affinity (EA), global hardness (M),

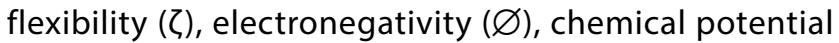
$\left(\mu_{c}\right)$, and electrophilicity index $(\omega)$ are given by the following formulas [31, 36, 37]:

$E_{\text {gap }}=E_{L U M O}-E_{\text {HOMO }}$

$\mathrm{IP}=-\mathrm{E}_{\mathrm{HOMO}}$

$\mathrm{EA}=-\mathrm{E}_{\mathrm{LUMO}}$

$\mu_{c}=-\left(\frac{\mathrm{IP}+\mathrm{EA}}{2}\right)$

$\emptyset=-\mu_{c}$

$M=\frac{I P-E A}{2}$

$\zeta=\frac{1}{M}$

$\omega=\frac{\mu_{c}^{2}}{2 M}$

Piezoelectric materials are characterized by the piezoelectric (d) and pyroelectric (p) coefficients.

$[38,39]$. The set of piezoelectricity equations is given by the relation (17):

$\left\{\begin{array}{l}D=\varepsilon^{T} E+d T \\ S=d E+S^{E} T\end{array}\right.$

$D$ : The electric displacement field $\left(C . m^{-1}\right), \varepsilon^{T}$ : permittivity $\left(\mathrm{F} \cdot \mathrm{m}^{-1}\right), \mathrm{E}$ : the electric field $\left(\mathrm{V} \cdot \mathrm{m}^{-1}\right), S^{E}$ : compliance, $\mathrm{T}$ : mechanical stress $\left(\mathrm{N} . \mathrm{m}^{-2}\right), d$ : piezoelectric constant $\left(\mathrm{C} . N^{-1}\right)$, S: strain $(\mathrm{m})$. The piezoelectric and pyroelectric coefficients are also given by the following relations:

$\left\{\begin{array}{l}d=\frac{\delta P}{\delta T} \\ p=\frac{\delta P}{\delta T_{e}}\end{array}\right.$

where Te is the temperature $[40,41]$.

\section{Results and discussion}

\section{1 optimized structure}

The optimized structure of the molecules doped with chlorine and fluorine are shown in Fig. 2. 


\subsection{Geometric properties}

Tables 1 and 2 respectively give us the interatomic distances and the valence angles of the various structures optimized according to the labels of the atoms. These optimized structures were obtained using the DFT (B3LYP /B3PW91) method with 6-311++G (d, p) basis set. From our results, it can be seen that, the geometrical parameters of the two molecules varies slightly when we move from one method to another. Equally, no imaginary frequency was observed after optimization of our systems. This led us to the conclusion that the optimized molecular systems are stable at all the level and basis set used. Thus, when we compare these interatomic distances and valence angle with those obtained in previous work on the DATVB undoped molecule [16], the values obtained after doping are clearly higher, this is certainly due to the addition of halogens in the systems which creates load shifting and makes the system attractive. So we can conclude that doping influences the structural geometry of these compounds.

\subsection{Optoelectronic properties}

Table 3 gives the values of the average electric field $(E)$, the magnetic field $(B)$, the phase celerity $\left(V_{p h}\right)$, the electric polarization density $(P)$, the electrical susceptibility $(\chi \mathrm{e})$, the relative dielectric constant $(\varepsilon)$, the refractive index $(n)$, the electrical displacement vector $(D)$, the radius $(\mathrm{R})$ and the volume $(\mathrm{V})$ of each molecule. These optoelectronic parameters were calculated applying the Eqs. $(1,2,3)$ given above. The electric polarization density values $(P)$ of the doped molecules are on average three times higher than that of the initial molecule studied by F. Tchangnwa Nya et al. [16]; similarly, the

Table 1 Bond lengths ( $\mathrm{A})$ in the molecules BCATVB and BFATVB obtained with B3LYP and B3PW91 using $6-311++G(d, p)$ basis set

\begin{tabular}{|c|c|c|c|c|c|}
\hline \multicolumn{3}{|l|}{ BCATVB } & \multicolumn{3}{|l|}{ BFATVB } \\
\hline Bond lengths & B3LYP & B3PW91 & Bond lengths & B3LYP & B3PW91 \\
\hline $\mathrm{R}(1,2)$ & 1.3975 & 1.3958 & $R(1,2)$ & 1.3996 & 1.3985 \\
\hline$R(1,4)$ & 1.3948 & 1.3925 & $R(1,4)$ & 1.3935 & 1.3906 \\
\hline $\mathrm{R}(1,20)$ & 1.0809 & 1.0819 & $R(1,20)$ & 1.0809 & 1.0818 \\
\hline$R(2,3)$ & 1.3849 & 1.3824 & $\mathrm{R}(2,3)$ & 1.3803 & 1.3771 \\
\hline $\mathrm{R}(2,21)$ & 1.0801 & 1.0813 & $\mathrm{R}(2,21)$ & 1.0806 & 1.0817 \\
\hline$R(3,5)$ & 1.3841 & 1.3819 & $R(3,5)$ & 1.3913 & 1.3908 \\
\hline $\mathrm{R}(3,19)$ & 1.7422 & 1.7318 & $R(3,19)$ & 1.7406 & 1.7299 \\
\hline $\mathrm{R}(4,8)$ & 1.4372 & 1.4353 & $\mathrm{R}(4,8)$ & 1.4381 & 1.4368 \\
\hline $\mathrm{R}(4,19)$ & 1.7498 & 1.74 & $\mathrm{R}(4,19)$ & 1.7509 & 1.741 \\
\hline$R(5,6)$ & 1.2495 & 1.3218 & $R(5,6)$ & 1.2372 & 1.2326 \\
\hline$R(5,7)$ & 1.3248 & 1.2435 & $\mathrm{R}(5,7)$ & 1.3356 & 1.329 \\
\hline$R(6,29)$ & 2.2122 & 1.8887 & $R(6,29)$ & 1.8235 & 1.7848 \\
\hline$R(7,28)$ & 1.9292 & 2.1722 & $R(7,28)$ & 1.5464 & 1.5204 \\
\hline $\mathrm{R}(8,9)$ & 1.3567 & 1.3548 & $\mathrm{R}(8,9)$ & 1.3562 & 1.3539 \\
\hline $\mathrm{R}(8,25)$ & 1.0854 & 1.0864 & $\mathrm{R}(8,25)$ & 1.0854 & 1.0864 \\
\hline $\mathrm{R}(9,10)$ & 1.4486 & 1.4458 & $\mathrm{R}(9,10)$ & 1.449 & 1.4467 \\
\hline $\mathrm{R}(9,24)$ & 1.0872 & 1.0882 & $\mathrm{R}(9,24)$ & 1.0872 & 1.0882 \\
\hline$R(10,11)$ & 1.409 & 1.4061 & $R(10,11)$ & 1.4088 & 1.4058 \\
\hline$R(10,12)$ & 1.4108 & 1.4078 & $R(10,12)$ & 1.4106 & 1.4075 \\
\hline$R(11,13)$ & 1.384 & 1.3819 & $R(11,13)$ & 1.3841 & 1.3822 \\
\hline$R(11,23)$ & 1.0852 & 1.0863 & $R(11,23)$ & 1.0852 & 1.0863 \\
\hline$R(12,14)$ & 1.3808 & 1.3788 & $R(12,14)$ & 1.3809 & 1.379 \\
\hline$R(12,26)$ & 1.0836 & 1.0847 & $R(12,26)$ & 1.0836 & 1.0847 \\
\hline$R(13,15)$ & 1.4054 & 1.4033 & $R(13,15)$ & 1.4052 & 1.403 \\
\hline$R(13,22)$ & 1.0849 & 1.0858 & $R(13,22)$ & 1.085 & 1.0859 \\
\hline$R(14,15)$ & 1.4098 & 1.4075 & $R(14,15)$ & 1.4097 & 1.4073 \\
\hline$R(14,27)$ & 1.0851 & 1.086 & $R(14,27)$ & 1.0851 & 1.0861 \\
\hline$R(15,16)$ & 1.3807 & 1.3758 & $R(15,16)$ & 1.381 & 1.3767 \\
\hline$R(16,17)$ & 1.0078 & 1.0069 & $\mathrm{R}(16,17)$ & 1.0078 & 1.007 \\
\hline$R(16,18)$ & 1.0078 & 1.0069 & $R(16,18)$ & 1.0078 & 1.007 \\
\hline
\end{tabular}

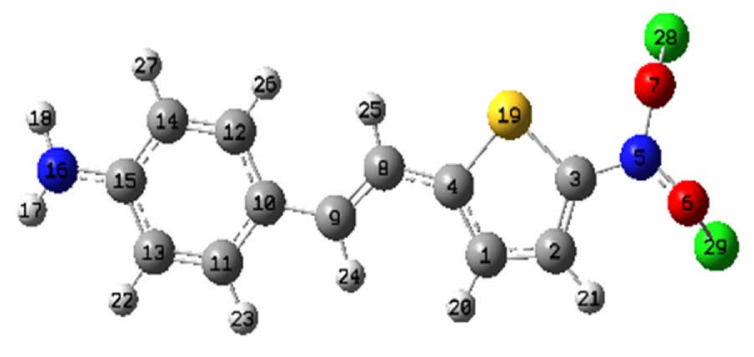

BCATVB

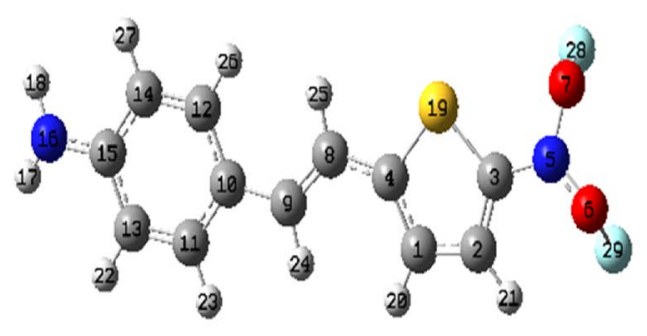

BFATVB

Fig. 2 Optimized structure of BCATVB and BFATVB respectively 
Table 2 Bond angles $\left({ }^{\circ}\right)$ of molecules BCATVB and BFATVB obtained with B3LYP and B3PW91 using 6-311+ +G $(d$, p) basis set

\begin{tabular}{|c|c|c|c|c|c|}
\hline \multicolumn{3}{|l|}{ BCATVB } & \multicolumn{3}{|l|}{ BFATVB } \\
\hline $\begin{array}{l}\text { Bond } \\
\text { angles }\end{array}$ & B3LYP & B3PW91 & $\begin{array}{l}\text { Bond } \\
\text { angles }\end{array}$ & B3LYP & B3PW91 \\
\hline$A(2,1,4)$ & 113.9875 & 113.8645 & $\mathrm{~A}(2,1,4)$ & 114.0183 & 113.883 \\
\hline$A(2,1,20)$ & 123.0144 & 123.1132 & $A(2,1,20)$ & 123.0089 & 123.1057 \\
\hline$A(4,1,20)$ & 122.998 & 123.0222 & $A(4,1,20)$ & 122.962 & 123.0007 \\
\hline$A(1,2,3)$ & 111.92 & 111.7218 & $A(1,2,3)$ & 111.7145 & 111.5487 \\
\hline$A(1,2,21)$ & 125.6196 & 125.8231 & $A(1,2,21)$ & 126.3913 & 126.4342 \\
\hline$A(3,2,21)$ & 122.4494 & 122.4443 & $A(3,2,21)$ & 121.8324 & 121.9662 \\
\hline$A(2,3,5)$ & 125.3756 & 125.3639 & $A(2,3,5)$ & 124.6904 & 124.825 \\
\hline$A(2,3,19)$ & 112.6723 & 112.7876 & $A(2,3,19)$ & 113.0337 & 113.1112 \\
\hline$A(5,3,19)$ & 121.9224 & 121.8088 & $A(5,3,19)$ & 122.2503 & 122.0247 \\
\hline$A(1,4,8)$ & 130.4629 & 130.5244 & $\mathrm{~A}(1,4,8)$ & 130.5272 & 130.6344 \\
\hline$A(1,4,19)$ & 110.8429 & 110.8779 & $A(1,4,19)$ & 110.8287 & 110.8455 \\
\hline $\mathrm{A}(8,4,19)$ & 118.6928 & 118.5968 & $\mathrm{~A}(8,4,19)$ & 118.6403 & 118.5167 \\
\hline$A(3,5,6)$ & 122.1193 & 118.2634 & $A(3,5,6)$ & 123.1674 & 123.0152 \\
\hline $\mathrm{A}(3,5,7)$ & 118.4468 & 122.0486 & $A(3,5,7)$ & 114.0183 & 118.2358 \\
\hline$A(6,5,7)$ & 118.593 & 118.6448 & $A(6,5,7)$ & 123.0089 & 118.0485 \\
\hline$A(5,6,29)$ & 112.8217 & 113.8935 & $A(5,6,29)$ & 118.3245 & 108.6791 \\
\hline$A(5,7,28)$ & 114.0322 & 112.9192 & $A(5,7,28)$ & 117.8759 & 109.1013 \\
\hline$A(4,8,9)$ & 124.6401 & 124.5784 & $A(4,8,9)$ & 108.3267 & 124.5964 \\
\hline$A(4,8,25)$ & 115.9634 & 115.9999 & $A(4,8,25)$ & 109.2145 & 115.9838 \\
\hline$A(9,8,25)$ & 119.395 & 119.4206 & $A(9,8,25)$ & 124.6245 & 119.4198 \\
\hline$A(8,9,10)$ & 127.5297 & 127.4009 & $A(8,9,10)$ & 115.9747 & 127.3997 \\
\hline$A(8,9,24)$ & 117.9276 & 117.9719 & $A(8,9,24)$ & 119.4007 & 117.9977 \\
\hline $\begin{array}{c}A(10, \\
9,24)\end{array}$ & 114.5417 & 114.6263 & $\begin{array}{c}A(10, \\
9,24)\end{array}$ & 127.5371 & 114.6025 \\
\hline $\begin{array}{l}A(9, \\
\quad 10,11)\end{array}$ & 119.1376 & 119.1506 & $\begin{array}{l}\mathrm{A}(9, \\
\quad 10,11)\end{array}$ & 117.9391 & 119.1473 \\
\hline $\begin{array}{l}\mathrm{A}(9, \\
\quad 10,12)\end{array}$ & 123.9042 & 123.8962 & $\begin{array}{l}\mathrm{A}(9, \\
\quad 10,12)\end{array}$ & 114.5238 & 123.9017 \\
\hline $\begin{array}{l}\mathrm{A}(11, \\
\quad 10,12)\end{array}$ & 116.958 & 116.9532 & $\begin{array}{l}\mathrm{A}(11, \\
\quad 10,12)\end{array}$ & 119.1338 & 116.9509 \\
\hline $\begin{array}{c}A(10, \\
11,13)\end{array}$ & 121.9905 & 122.0045 & $\begin{array}{c}A(10, \\
11,13)\end{array}$ & 123.9079 & 122.0063 \\
\hline $\begin{array}{c}A(10, \\
\quad 11,23)\end{array}$ & 119.0286 & 119.0151 & $\begin{array}{c}A(10, \\
11,23)\end{array}$ & 116.9582 & 119.0251 \\
\hline $\begin{array}{c}A(13, \\
\quad 11,23)\end{array}$ & 118.9806 & 118.9803 & $\begin{array}{l}A(13, \\
11,23)\end{array}$ & 121.9913 & 118.9686 \\
\hline $\begin{array}{c}\mathrm{A}(10, \\
\quad 12,14)\end{array}$ & 121.5712 & 121.5876 & $\begin{array}{l}\mathrm{A}(10, \\
12,14)\end{array}$ & 119.0364 & 121.5852 \\
\hline $\begin{array}{c}A(10, \\
\quad 12,26)\end{array}$ & 120.081 & 120.0817 & $\begin{array}{l}A(10, \\
12,26)\end{array}$ & 118.9722 & 120.0866 \\
\hline $\begin{array}{c}A(14, \\
\quad 12,26)\end{array}$ & 118.3478 & 118.3306 & $\begin{array}{c}A(14, \\
12,26)\end{array}$ & 121.5703 & 118.3279 \\
\hline $\begin{array}{l}A(11, \\
\quad 13,15)\end{array}$ & 120.4073 & 120.4223 & $\begin{array}{c}A(11, \\
\quad 13,15)\end{array}$ & 120.0806 & 120.427 \\
\hline $\begin{array}{l}A(11, \\
\quad 13,22)\end{array}$ & 119.9468 & 119.9202 & $\begin{array}{c}A(11, \\
\quad 13,22)\end{array}$ & 118.3489 & 119.9123 \\
\hline $\begin{array}{l}A(15, \\
\quad 13,22)\end{array}$ & 119.6458 & 119.6572 & $\begin{array}{l}A(15, \\
13,22)\end{array}$ & 120.4088 & 119.6606 \\
\hline $\begin{array}{c}A(12, \\
14,15)\end{array}$ & 120.8217 & 120.8398 & $\begin{array}{c}A(12, \\
14,15)\end{array}$ & 119.947 & 120.8484 \\
\hline
\end{tabular}

Table 2 (continued)

\begin{tabular}{|c|c|c|c|c|c|}
\hline \multicolumn{3}{|l|}{ BCATVB } & \multicolumn{3}{|l|}{ BFATVB } \\
\hline $\begin{array}{l}\text { Bond } \\
\text { angles }\end{array}$ & B3LYP & B3PW91 & $\begin{array}{l}\text { Bond } \\
\text { angles }\end{array}$ & B3LYP & B3PW91 \\
\hline $\begin{array}{c}\text { A }(12, \\
\quad 14,27)\end{array}$ & 119.7855 & 119.7539 & $\begin{array}{c}A(12, \\
14,27)\end{array}$ & 119.6441 & 119.7436 \\
\hline $\begin{array}{l}A(15, \\
\quad 14,27)\end{array}$ & 119.3925 & 119.4061 & $\begin{array}{c}A(15, \\
14,27)\end{array}$ & 120.8241 & 119.4079 \\
\hline $\begin{array}{l}A(13, \\
15,14)\end{array}$ & 118.2506 & 118.1924 & $\begin{array}{c}A(13, \\
15,14)\end{array}$ & 119.7852 & 118.1819 \\
\hline $\begin{array}{c}A(13, \\
15,16)\end{array}$ & 121.0359 & 121.0702 & $\begin{array}{c}A(13, \\
15,16)\end{array}$ & 119.3906 & 121.07 \\
\hline $\begin{array}{c}A(14, \\
15,16)\end{array}$ & 120.67 & 120.6965 & $\begin{array}{c}A(14, \\
15,16)\end{array}$ & 118.247 & 120.7065 \\
\hline $\begin{array}{c}A(15, \\
16,17)\end{array}$ & 117.9351 & 117.9278 & $\begin{array}{c}A(15, \\
16,17)\end{array}$ & 121.035 & 117.7421 \\
\hline $\begin{array}{c}A(15, \\
16,18)\end{array}$ & 117.9461 & 117.9371 & $\begin{array}{c}A(15, \\
16,18)\end{array}$ & 120.676 & 117.7623 \\
\hline $\begin{array}{c}A(17, \\
16,18)\end{array}$ & 114.3901 & 114.496 & $\begin{array}{c}A(17, \\
16,18)\end{array}$ & 117.8788 & 114.3145 \\
\hline$A(3,19,4)$ & 90.5738 & 90.7439 & $A(3,19,4)$ & 117.9063 & 90.6111 \\
\hline
\end{tabular}

values of $E, \varepsilon, n, D$ are much higher compare the results with the previous similar findings in previous works [15, 42]. These results led us to conclude that the doping of these materials with chlorine and fluorine promotes the dynamics and distribution of charges within these molecules. This makes them more likely to apply optoelectronic applications in particular in renewable energy for the production of photovoltaic cells, organic light emitting diodes and photonic devices.

Table 3 Average electric field (E), electric polarization density $(P)$, electrical susceptibility $(\chi e)$, relative dielectric constant $(\varepsilon)$, refractive index $(n)$, phase celerity $\left(V_{p h}\right)$, magnetic field (B), electric displacement vector $(D)$, radius $(R)$ and volume $(V)$ of molecules BCATVB and BFATVB obtained with B3LYP and B3PW91 using $6-311++G(d, p)$ basis set

\begin{tabular}{|c|c|c|c|c|c|}
\hline \multicolumn{3}{|l|}{ BCATVB } & \multicolumn{3}{|l|}{ BFATVB } \\
\hline Parameters & B3LYP & B3PW91 & Parameters & B3LYP & B3PW91 \\
\hline$E\left(V m^{-1}\right) 10^{8}$ & 7.36 & 7.48 & $E\left(V m^{-1}\right) 10^{8}$ & 8.49 & 8.34 \\
\hline$P\left(\mathrm{Cm}^{-2}\right) 10^{-2}$ & 25.70 & 30.98 & $P\left(\mathrm{Cm}^{-2}\right) 10^{-2}$ & 35.30 & 31.08 \\
\hline$\chi_{e}$ & 39.44 & 46.77 & $\chi_{e}$ & 46.95 & 41.08 \\
\hline$\varepsilon_{r}$ & 40.44 & 47.77 & $\varepsilon_{r}$ & 47.95 & 42.08 \\
\hline$\varepsilon 10^{-10}$ & 3.58 & 4.22 & $\varepsilon 10^{-10}$ & 4.24 & 3.72 \\
\hline$n$ & 6.35 & 6.91 & $n$ & 6.92 & 6.48 \\
\hline$V_{p h}\left(m \cdot s^{-1}\right) \cdot 10^{8}$ & 0.47 & 0.44 & $V_{p h}\left(m \cdot s^{-1}\right) \cdot 10^{8}$ & 0.43 & 0.46 \\
\hline$B\left(V \cdot m^{-2} s\right)$ & 15.65 & 17 & $B\left(V \cdot m^{-2} s\right)$ & 19.74 & 18.13 \\
\hline$D .10^{-2}$ & 26.34 & 31.56 & $D .10^{-2}$ & 35.99 & 31.02 \\
\hline$R(\AA)$ & 5.65 & 5.27 & $R\left(A^{\circ}\right)$ & 5.06 & 5.17 \\
\hline$V_{m}\left(m^{3}\right) \cdot 10^{-30}$ & 180.36 & 146.36 & $V_{m}\left(m^{3}\right) \cdot 10^{-30}$ & 129.55 & 138.19 \\
\hline
\end{tabular}




\subsection{Transport properties and energy analysis}

The energy difference between the HUMO-LUMO borders is called energy gap $\left(E_{\text {gap }}\right)$ [42]. The values of the energies $E_{\text {HOMO }}$ and $E_{\text {LUMO }}$ of these molecules, calculated are recorded in Table 4. $E_{\text {gap }}$ is a critical parameter for determining the electrical transport properties of a molecule. By using the values of the energies $E_{\text {HOMO }}$ and $E_{\text {LUMO }}$ for a molecule, the global descriptors of the chemical reactivity of the molecules such as the global hardness $(M)$, the chemical potential $\left(\mu_{c}\right)$, the flexibility $(\zeta)$, the electronegativity $(\varnothing)$, the ionization potential (IP), the electronic affinity $(E A)$ and the electrophilicity index $(\omega)$ were calculated using the mathematical formulas given earlier. These

Table $4 \mathrm{E}_{\mathrm{LUMO}}, \mathrm{E}_{\mathrm{HOMO}}, \mathrm{E}_{\mathrm{gap}}$, chemical potential $\left(\mu_{c}\right)$, electronegativity $(\emptyset)$, absolute hardness $(M)$, softness $(\zeta)$, ionization potential (IP), Electronic affinity $(E A)$ and electrophilic index $(\omega)$ of the molecules BCATVB and BFATVB obtained using B3LYP and B3PW91 with $6-311 \mathrm{G}++(d, p)$ basis set

\begin{tabular}{|c|c|c|c|c|c|}
\hline \multicolumn{3}{|l|}{ BCATVB } & \multicolumn{3}{|l|}{ BFATVB } \\
\hline Parameters & B3LYP & B3PW91 & Parameters & B3LYP & B3PW91 \\
\hline $\mathrm{E}_{\text {LUMO }}(\mathrm{eV})$ & -4.64 & -4.48 & $\mathrm{E}_{\text {LUMO }}(\mathrm{eV})$ & -4.52 & -4.34 \\
\hline $\mathrm{E}_{\text {номо }}(\mathrm{eV})$ & -5.89 & -5.88 & $\mathrm{E}_{\text {номо }}(\mathrm{eV})$ & -5.91 & -5.89 \\
\hline$E_{\text {gap }}(e V)$ & 1.25 & 1.40 & $E_{\text {gap }}(e V)$ & 1.39 & 1.54 \\
\hline$\mu_{c}$ & 5.27 & 5.18 & $\mu_{c}$ & 5.22 & 5.12 \\
\hline$\emptyset(\mathrm{eV})$ & -5.27 & -5.18 & $\emptyset(\mathrm{eV})$ & -5.22 & -5.12 \\
\hline $\mathrm{M}(\mathrm{eV})$ & 0.63 & 0.70 & $\mathrm{M}(\mathrm{eV})$ & 0.69 & 0.78 \\
\hline$\zeta(1 / \mathrm{eV})$ & 1.59 & 1.42 & $\zeta(1 / \mathrm{eV})$ & 1.45 & 1.28 \\
\hline IP & 5.89 & 5.88 & IP & 5.91 & 5.89 \\
\hline EA & 4.64 & 4.48 & EA & 4.52 & 4.34 \\
\hline$\omega$ & 22.04 & 19.16 & $\omega$ & 19.74 & 16.80 \\
\hline
\end{tabular}

values are also recorded in Table 3. We observed that the gap energy $\left(E_{\text {gap }}\right)$ of these two molecules varies between $1 \mathrm{eV}$ and $1.5 \mathrm{eV}$, these energies being less than $3 \mathrm{eV}$. The calculated parameters shows that these materials are good semiconductors which further confirms the results presented above, so these materials can have applications in electronics, optoelectronics and photonics. [43-47]. Concerning the frontier molecular orbitals of our molecules. The highest occupied and the lowest unoccupied molecular orbitals (HOMO and LUMO respectively), are the most important parameters which permit us to know how the molecule interacts and explain the structure and reactivity of the molecules [35]. The HOMO which is nucleophilic or electron-donating, represent the capacity of a molecule to give an electron while LUMO which is electrophilic or electron-accepting, represent the capacity of a molecule to receive an electron. Figure 3 present the 3D molecular orbital diagrams. From this figure we can see that the halogen (chlorine and fluorine) atoms participates favorably in the charge-transfer to improve the electronic dynamism which reigns within these compounds. (Table 4)

\subsection{Nonlinear optical properties}

The organic compounds exhibiting a high hyperpolarisability are those which contain electron donor group and an electron attractor group interacting through a system of conjugated double bonds as observed in our studied systems. To fully understand the non-linear optical (NLO) properties, certain parameters such as dipole moment, polarizability, anisotropy, the first and second hyperpolarisability were calculated in this work. These parameters were obtained by applying the mathematical formulas (4,

\section{BCATVB}

LUMO
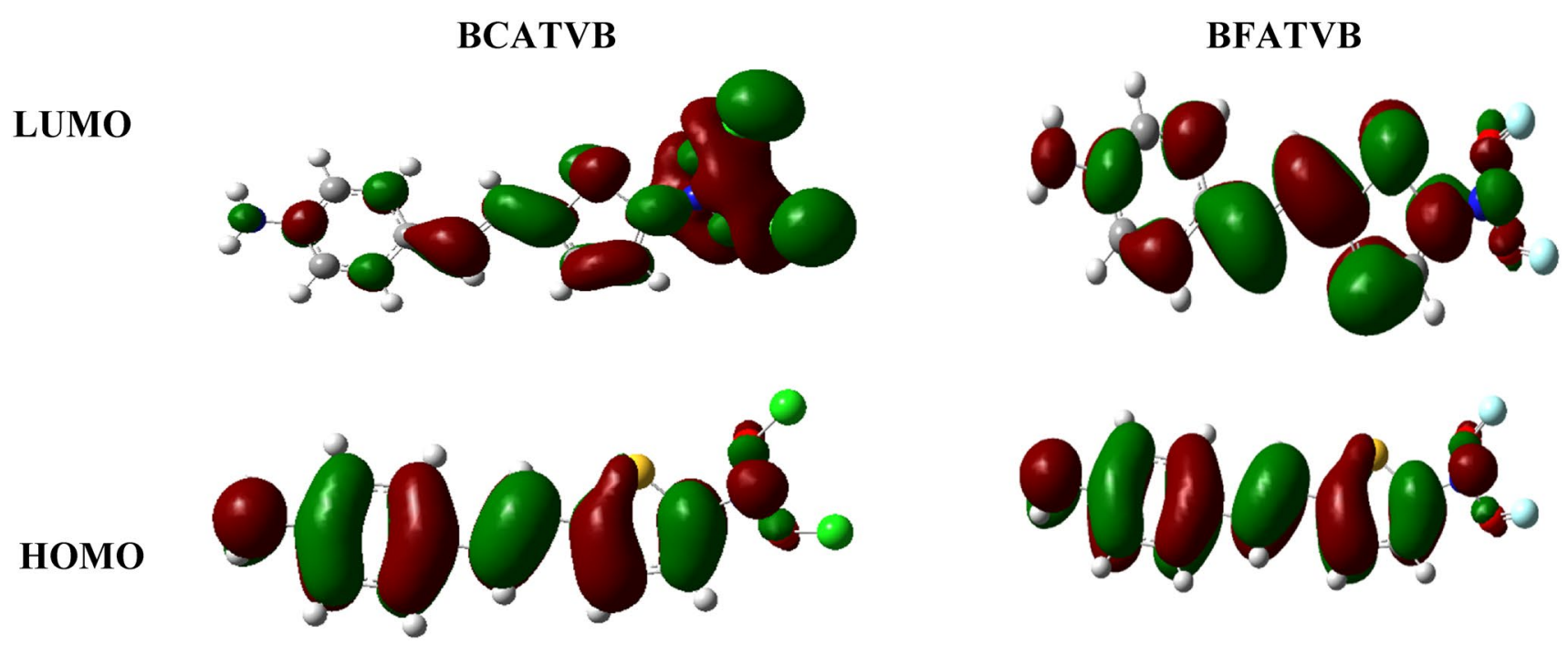

Fig. 3 Diagram of the LUMO and HOMO molecular orbitals of the BCATVB and BFATVB structures obtained at the B3LYP/6-311+ + G (d, p) level of theory 
$5,6,7,8)$ giving above. Table 5 presents these different calculated values. We note that the values of the dipole moments are around 13 Debye with B3LYP and B3PW91 and found around 5 Debye with CAM-B3LYP. We can therefore conclude that these different materials are polar as reported in the literature $[33,48]$. Moreover when we observe the six components of the asymmetric tensor of polarizability as well as the ten components of the tensor of hyperpolarizability of the first order we note that only the components $\alpha_{\mathrm{xx}}$ and $\beta_{\mathrm{xxx}}$ have larger values, we can therefore conclude that these are parameters which give the linear and non-linear character respectively of these molecules. By comparing our values of the first order hyperpolarizabilities calculated with B3LYP, B3PW91 and CAM-B3LYP with the experimental values of para-nitroaniline $(p-N A)\left(\beta_{m o l}(e s u)=9261,32.10^{-33}\right)[49]$ and $p-N a / C A M-$ B3LYP which is a reference organic molecule for the study of non-linear optical parameters of materials organic, we can see that our values are much higher than that of this referencing molecule, which suggests that our studied systems have very good NLO properties. In addition, our $\beta_{m o l}$ and $\mu$ values are very much higher than those of other NLO compounds found in the other work [50-55] obtained with the same methods at the theoretical level and experimental. These result show us that these doped molecules (BCATVB and BFATVB) are very good materials for applications in non-linear optics namely in frequency shift, optical modulation, optical communication, optical logic, optical memories for emerging technologies in fields such as telecommunications, signal processing devices, dynamic imaging, data storage, computer devices and optical connectors $[13,14,55]$.

\subsection{Piezoelectric properties}

Piezoelectricity is a renewable energy whose principle is to produce electricity thanks to a pressure exerted on a material. In 1880, the brothers Pierre and Jacques Curie undertook a theoretical and experimental study of the piezoelectric effect, which made it possible to establish the conditions that a material must meet to be piezoelectric. This work is considered to be the discovery of the direct piezoelectric
Table 5 Dipolar moment ( $\mu$ (Debye)), average polarisability $\left.\left(\langle\alpha\rangle(\mathrm{esu}) 10^{-24}\right)\right)$, anisotropy $\left(\Delta \alpha(\mathrm{esu}) \cdot 10^{-24}\right)$, first order hyperpolarisability $\left(\beta_{\mathrm{mol}}(\mathrm{esu}) 10^{-33}\right)$ and second order hyperpolarisability ( $\gamma(\mathrm{esu}) 10^{-36}$ ) of the molecules BCATVB and BFATVB obtained using B3LYP and B3PW91 with $6-311 \mathrm{G}++(\mathrm{d}, \mathrm{p})$ basis set

\begin{tabular}{|c|c|c|c|c|c|c|c|}
\hline \multicolumn{3}{|l|}{ BCATVB } & \multicolumn{3}{|l|}{ BFATVB } & \multicolumn{2}{|l|}{$\mathrm{p}-\mathrm{Na}$} \\
\hline Parameters & B3LYP & CAM-B3LYP & B3PW91 & B3LYP & CAM-B3LYP & B3PW91 & CAM-B3LYP \\
\hline$\mu$ & 13.89 & 4.52 & 13.60 & 13.73 & 5.68 & 12.89 & 7.48 \\
\hline$\alpha_{x x}$ & 748.61 & 461.13 & 718.72 & 666.89 & 410.05 & 631.63 & 143.49 \\
\hline$\alpha_{x y}$ & -31.85 & 2.36 & -31.33 & 21.58 & 4.11 & 20.63 & 0.003 \\
\hline$\alpha_{y y}$ & 250.61 & 202.07 & 241.72 & 198.68 & 181.02 & 193.59 & 98.20 \\
\hline$\alpha_{x z}$ & -17.48 & 0.000013 & 14.92 & 4.45 & -0.20 & 3.75 & -0.33 \\
\hline$\alpha_{y z}$ & 6.79 & -0.53 & -6.74 & 5.47 & -0.73 & 5.42 & -0.14 \\
\hline$\alpha_{\mathrm{zz}}$ & 146.13 & 117.37 & 142.19 & 114.82 & 102.63 & 112.12 & 50.41 \\
\hline$\langle\alpha\rangle$ & 56.58 & 38.56 & 54.47 & 48.43 & 34.26 & 46.31 & 15.09 \\
\hline$\Delta \alpha$ & 58.82 & 32.51 & 56.30 & 54.15 & 29.00 & 50.87 & 8.44 \\
\hline$\beta_{x x x}$ & $46,950.08$ & -5413.52 & $41,463.09$ & $39,580.78$ & 3706.81 & $34,923.26$ & 1561.96 \\
\hline$\beta_{x x y}$ & -3971.98 & -263.16 & -3526.98 & 2213.53 & 307.26 & 1983.17 & 0.007 \\
\hline$\beta_{\text {xyy }}$ & 568.93 & 21.48 & 516.44 & -119.12 & -104.74 & -102.14 & -142.09 \\
\hline$\beta_{y y y}$ & 547.52 & -131.07 & 488.08 & -186.98 & 24.49 & -171.79 & 0.0002 \\
\hline$\beta_{\mathrm{xxz}}$ & -1126.53 & 110.44 & 578.08 & 562.46 & 33.10 & 345.96 & -13.25 \\
\hline$\beta_{x y z}$ & 199.61 & 4.87 & -134.76 & 14.27 & -7.21 & 1.68 & -0.0004 \\
\hline$\beta_{y y z}$ & -224.25 & -16.03 & 205.04 & 21.84 & 10.35 & 21.64 & -2.19 \\
\hline$\beta_{\mathrm{xzz}}$ & 2.18 & 36.35 & -35.77 & -127.61 & -51.32 & -128.15 & -59.71 \\
\hline$\beta_{y z z}$ & -55.56 & -0.64 & -46.56 & -5.33 & -1.61 & -6.97 & -0.0006 \\
\hline$\beta_{\mathrm{zzz}}$ & -11.18 & 118.78 & -19.12 & -48.29 & 29.22 & -45.24 & -7.51 \\
\hline$\beta_{\mathrm{mol}}$ & $411,817.44$ & $46,404.05$ & $363,403.83$ & $340,298.55$ & $30,814.59$ & $300,141.05$ & $14,261.41$ \\
\hline$\gamma_{x x x x}$ & 20.33 & - & 3.92 & 10.27 & - & 9.48 & - \\
\hline$\gamma_{x x y y}$ & 8.15 & - & 2.26 & 5.11 & - & 4.57 & - \\
\hline$\gamma_{x x z z}$ & 54.57 & - & 37.67 & -40.09 & - & -41.81 & - \\
\hline$\gamma_{\text {yyyy }}$ & 19.23 & - & 4.99 & 11.63 & - & 10.69 & - \\
\hline$\gamma_{\text {yyzz }}$ & 68.54 & - & 48.91 & 20.06 & - & 20.07 & - \\
\hline$\gamma_{\mathrm{zzzz}}$ & 1773.99 & - & 1535.92 & -4136.25 & - & -4443.01 & - \\
\hline$\gamma$ & 415.21 & - & 344.51 & -828.83 & - & 891.43 & - \\
\hline
\end{tabular}


effect [56]. So-called piezoelectric materials have the property of converting mechanical energy into electrical energy: under the effect of mechanical stress, the electrical polarization of the crystal is modified. Table 6 presents the values of the piezoelectric coefficients (d) and the average values of the pyroelectric coefficient ( $p$ ) applying mathematical formulas presented previously. It should be noted that the volume obtained with the Gaussian software for a molecule, using the same method, the same basis of calculation and the same functional are not always the same. This may be due to the indefinite position of atoms in space. This same remark has been mentioned in the literature [55], this phenomenon allows the increase or decrease of the volume which causes a reorientation of the microscopic dipoles according to the literature [56] therefore the calculation of the piezoelectricity parameters is possible. From Table 6, it can be seen that the values of the piezoelectric coefficient of the fluorinated molecule are above that of the reference organic molecule polyvinylidene fluoride (PVDF), which values varies between 12 and $23 p C . N^{-1}$ [57-59]. We can therefore conclude that these molecules are piezoelectric materials and can be used in the manufacture of medical ultrasound or non-destructive testing equipment, components used in radio and telecommunications as a frequency reference or as a microphone or loudspeaker [56].

In this study the influence of temperature on the pyroelectric coefficient was also observed, the temperature was raised from 250 to $500 \mathrm{~K}$ with a step of $50 \mathrm{~K}$.Table 7 presents the results obtained. We note that the pyroelectric coefficient is related to the variations of the elementary dipoles. It can be concluded that these molecules tend to lose their pyroelectric activity when the temperature increases. This result is also observed in the literature [60].

\subsection{Thermodynamic properties}

Zero vibrational point energy (ZPVE), Gibbs free energy $(G)$, thermal energy $(E)$, entropy $(S)$, enthalpy $(H)$, Constant Volume Heat Capacity (CV) were calculated at temperature $\mathrm{Te}=298.15 \mathrm{~K}$ and pressure $\mathrm{P}=1 \mathrm{~atm}$. The results are recorded in Table 7. It is noted that these parameters are more important with the fluorinated molecule. This is simply due to the fact that, fluorine is more electronegative

Table 6 Piezoelectric coefficient (d) and pyroelectric coefficient ( $p$ ) of the molecules BCATVB and BFATVB obtained using B3LYP and B3PW91 with 6-311G $++(d, p)$ basis set

\begin{tabular}{|c|c|c|c|c|c|}
\hline \multicolumn{3}{|l|}{ BCATVB } & \multicolumn{3}{|l|}{ BFATVB } \\
\hline Parameters & B3LYP & B3PW91 & Parameters & B3LYP & B3PW91 \\
\hline$d\left(p C \cdot N^{-1}\right)$ & 10.18 & 11.14 & $d\left(p C \cdot N^{-1}\right)$ & 23.41 & 29.72 \\
\hline \multicolumn{2}{|c|}{$\mathrm{p}\left(\mu \mathrm{C} \cdot \mathrm{m}^{-2} \cdot \mathrm{K}^{-1}\right) 1032.60$} & 1104 & \multicolumn{2}{|c|}{$\mathrm{p}\left(\mu \mathrm{C} \cdot \mathrm{m}^{-2} \cdot \mathrm{K}^{-1}\right) 1095.40$} & 997.25 \\
\hline
\end{tabular}

Table 7 Variation of the pyroelectric coefficient as a function of the temperature of the molecules BCTAVB and BFTAVB obtained using B3LYP and B3PW91 with 6-311G $++(d, p)$ basis set

\begin{tabular}{|c|c|c|c|c|c|}
\hline \multicolumn{3}{|l|}{ BCATVB } & \multicolumn{3}{|l|}{ BFATVB } \\
\hline $\begin{array}{l}\text { Tempera- } \\
\text { tures }\end{array}$ & B3LYP & B3PW91 & $\begin{array}{l}\text { Tempera- } \\
\text { tures }\end{array}$ & B3LYP & B3PW91 \\
\hline $250 \mathrm{~K}$ & 1236.80 & 1202 & $250 \mathrm{~K}$ & 1424.10 & 1298 \\
\hline $300 \mathrm{~K}$ & 973.15 & 928.02 & $300 \mathrm{~K}$ & 1030.81 & 951.22 \\
\hline $350 \mathrm{~K}$ & 917.59 & 895.01 & $350 \mathrm{~K}$ & 991.48 & 962.62 \\
\hline $400 \mathrm{~K}$ & 828.57 & 694.93 & $400 \mathrm{~K}$ & 859.08 & 811.28 \\
\hline $450 \mathrm{~K}$ & 733.66 & 665.24 & $450 \mathrm{~K}$ & 738.76 & 715.51 \\
\hline $500 \mathrm{~K}$ & 733.08 & 581.10 & $500 \mathrm{~K}$ & 688.61 & 646.48 \\
\hline
\end{tabular}

than chlorine. We also observe that the entropy of the doped materials is higher than that of the original molecule, which confirms what was said previously, the charge dynamics of the doped molecules are higher than its original molecule at the same temperature. This result further demonstrates that these doped materials have a high chemical reactivity and a high thermal resistivity, hence their application in the fields cited above. (Table 8)

\section{Conclusion}

In this study, we addressed the effect of doping with halogens (chlorine and fluorine) on the 4- [2- (2-N, N-dihydroxy amino thiophene) vinyl] benzenamine (DATVB) molecule. This study were done using DFT methods at the (B3LYP, CAM-B3LYP and B3PW91) levels of the theory and with the $6-311++g *$ basis set. Some interesting results were found. The new materials resulting from this doping are 4-[2-(2(5-(bis (chlorooxy) amino) thiophene) vinyl] benzenamine (BCATVB) and 4-[2-(2-(5-(bis (fluorooxy) amino) thiophene) vinyl] benzenamine (BFATVB). From this investigation, we found that, halogen doping systematically influences the structural, optoelectronic, nonlinear optical and thermodynamic properties. These properties are more interesting when compared to the undoped DATVB molecule. The value of the gap energy range between 1 and $1.5 \mathrm{ev}$, value less than $3 \mathrm{ev}$, shows that these doped materials are good semiconductors. In addition, these $\mathrm{E}_{\text {gap }}$, for doped molecules are smaller than the theoretical values of the DATVB molecule studied in the literature. We believe that the intrinsic conductivity, optical transitions, or electronic transions of these molecules vary greatly. The piezoelectric coefficients of fluorine-doped molecule (BFATVB) calculated at the B3LYP and B3PW91 levels are greater than the experimental values of the piezoelectric reference molecule $(\mathrm{p}-\mathrm{Na})$ found in the literature. This result opens up another field of application of this molecule in piezoelectricity as in the manufacture of 
Table 8 Zero Vibrational Point Energy (ZPVE), Gibbs free energy (G), Thermal Energy (E), Entropy (S), Enthalpy (H), Constant Volume Calorific Capacity (Cv), of the molecules BCATVB and BFATVB Obtained using B3LYP and B3PW91 with $6-311 \mathrm{G}++(\mathrm{d}, \mathrm{p})$ basis set at constant temperature and pressure

\begin{tabular}{|c|c|c|c|c|c|}
\hline \multicolumn{3}{|l|}{ BCATVB } & \multicolumn{3}{|l|}{ BFATVB } \\
\hline Parameters & B3LYP & B3PW91 & Parameters & B3LYP & B3PW91 \\
\hline ZPVE (kcal.mol ${ }^{-1}$ ) & 125.58 & 126.10 & ZPVE (kcal.mol ${ }^{-1}$ ) & 126.19 & 126.75 \\
\hline $\mathrm{G}\left(\mathrm{kcal} . \mathrm{mol}^{-1}\right)$ & 93.57 & 94.12 & $\mathrm{G}\left(\mathrm{kcal} . \mathrm{mol}^{-1}\right)$ & 95.36 & 95.86 \\
\hline $\mathrm{E}\left(\mathrm{kcal} . \mathrm{mol}^{-1}\right)$ & 137.56 & 138.04 & $\mathrm{E}\left(\mathrm{kcal} . \mathrm{mol}^{-1}\right)$ & 137.82 & 138.34 \\
\hline S (cal/mol. Kelvin) & 149.52 & 149.27 & S (cal/mol. Kelvin) & 144.41 & 144.47 \\
\hline $\mathrm{H}\left(\mathrm{kcal}^{\mathrm{mol}}{ }^{-1}\right)$ & 138.15 & 138.63 & $\mathrm{H}\left(\mathrm{kcal}^{\mathrm{mol}}{ }^{-1}\right)$ & 138.41 & 138.94 \\
\hline $\mathrm{C}_{\mathrm{v}}(\mathrm{Cal} / \mathrm{mol}$. Kelvin $)$ & 69.06 & 68.88 & $\mathrm{C}_{\mathrm{v}}(\mathrm{Cal} / \mathrm{mol}$. Kelvin$)$ & 68.42 & 68.16 \\
\hline
\end{tabular}

medical ultrasound or non-destructive testing equipment, components used in radio and telecommunications as a frequency reference or as a microphone or loudspeaker and many more. The thermodynamic properties obtained show that they have a high chemical reactivity and a high thermal resistivity. The large values of the average electric field, first molecular hyperpolarizability, total dipole moment, average polarizability, refractive index, electric susceptibility and small value of the dielectric constant of our molecule suggest the potential applications of the molecule in the development of nonlinear optical materials.

Acknowledgement We are thankful to the Council of Scientific and Industrial Research (CSIR), India for financial support through Emeritus Professor Scheme (Grant No21 (0582)/03/EMR-II) to late Prof. A.N. Singh of the Physics Department, Bahamas Hindu University, India which enabled him to purchase the Gaussian Software. We are most grateful to Late Emeritus Prof. A.N.

\section{Compliance with ethical standards}

Conflict of interest The authors declare that there is no conflict of interest as concern this article.

Open Access This article is licensed under a Creative Commons Attribution 4.0 International License, which permits use, sharing, adaptation, distribution and reproduction in any medium or format, as long as you give appropriate credit to the original author(s) and the source, provide a link to the Creative Commons licence, and indicate if changes were made. The images or other third party material in this article are included in the article's Creative Commons licence, unless indicated otherwise in a credit line to the material. If material is not included in the article's Creative Commons licence and your intended use is not permitted by statutory regulation or exceeds the permitted use, you will need to obtain permission directly from the copyright holder. To view a copy of this licence, visit http://creativecommons.org/licenses/by/4.0/.

\section{References}

1. Tang CW, VanSlyke SA (1987) Organic electroluminescent diodes. Appl Phys Lett 51:913-915. https://doi. org/10.1063/1.98799
2. Jonas F, Heywang G, Schmidtberg W, Heinze J, Dietrich M (1989) Neue polythiophene, verfahren zu ihrer herstellung und ihre verwendung, EP patent application EP19,890,106,236. https://doi.org/10.1063/1.4998509

3. Kivelson S, Chapman OL (1983) Polyacene and a new class of quasi-one-dimensional conductors. Phys Rev B 28:7236-7243. https://doi.org/10.1103/PhysRevB.28.7236

4. Ramkumar S, Manoharan S, Anandan S (2012) Synthesis of $D-(\pi-A)_{2}$ organic chromophores for dye-sensitized solar cells. Dyes Pigments 94:503-511. https://doi.org/10.1016/j.dyepi g.2012.02.016

5. Marder SR, Beratan DN, Cheng LT (1993) Approaches for optimizing the first electronic hyperpolarizability of conjugated organic molecules. Science 261:186-189. https://doi. org/10.1126/science.252.5002.103

6. Gorman CB, Marder SR (1996) Effect of molecular polarization on bond-length alternation, linear polarizability, first and second hyperpolarizability in donoracceptor polyenes as a function of chain length. Chem Mater 7:215-220. https://doi. org/10.1021/cm00049a033

7. Marder SR, Kippelen B, Jen AKY, Peyghammbarian N (1997) Design and synthesis of chromophores and polymers for electrooptic and photorefractive applications. Nature 388:845-851

8. Kanis DR, Ratner MA, Marks TJ (1994) Design and construction of molecular assemblies with large second-order optical nonlinearities. Quantum Chem Asp Chem Rev 94:195-242

9. Lamere JF, Lacroix PG, Farfan N, Rivera JM, Santillanc R, Nakatani K (2006) Synthesis, characterization and nonlinear optical (NLO) properties of a push-pull bisboronate chromophore with a potential electric field induced NLO switch. J Mater Chem 16:2913-2920

10. Pron A, Boulanger B (2002) Processible conjugated polymers: from organic semiconductors to organic metals and superconductors. Prog Polym Sci 27:135-190

11. Bürgi HSL, Richards TJ, Friend RH (2003) Close look at charge carrier injection in polymer field-effect transistors. J Appl Phys 94:6129

12. Senge MO, Fazekas M, Notaras EGA, Blau WJ, Zawadzka M, Locos OB, Ni Mhuircheartaigh EM (2007) Nonlinear optical properties of porphyrins. Adv Mater 19(19):2737-2774. https://doi. org/10.1002/adma.200601850

13. Karakas A, El Kouari Y, Migalska-Zalas A, Sahraoui B (2012) Abinitio calculations on static and dynamic third-order optical nonlinearity of azo-azulenes. Photonics Lett Pol 4(1):17-19

14. Ortyl E, Chan SW, Nunzi JM, Kucharski S (2006) Second harmonic generation by all-optical poling and its relaxation in the polymer films containing azo sulfonamide chromophores. Opt 
Mater (Amst) 29(2-3):268-272. https://doi.org/10.1016/j.optma t.2005.09.070

15. Mveme CDD, Tchangnwa Nya F, Ejuh GW, Kamsi RAY, Ndjaka JMB (2020) Density functional theory study of optoelectronic, nonlinear optical, piezoelectric and thermodynamic properties of poly (3,4-ethylenedioxythiophene), poly(3,4-ethylenedioxyselenophene) and their derivatives. Opt Quantum Electron 52:1-16

16. Tchangnwa Nya F, Ejuh GW, Ndjaka JMB (2017) Theoretical study of optoelectronic and thermodynamic properties of molecule 4-[2-(2-N, N-dihydroxy amino thiophene) vinyl] benzanamine: influence of hydroxyl position. Mater Lett 202:89-95. https:// doi.org/10.1016/j.matlet.2017.05.064

17. Chen W, Yu G, Jin P, Li Z-R, Huang X-R (2011) The heavier, the betterdincreased first hyperpolarizabilities in M@Calix[4]pyrrole ( $\mathrm{M} 1 / 4 \mathrm{Na}$ and K). J Comput Theor Nanosci 8:2482-2487

18. Hohenberg P, Kohn W (1964) Inhomogeneous electron gas. Phys Rev 136(3):864-871

19. Kohn W, Sham LJ (1965) Self-consistent equations including exchange and correlation effects. Phys Rev 140(4):1133-1138

20. Dennington R, Keith T, Millam J (2016) Gauss view, version 6. Semichem Inc, Shawnee Mission

21. Becke AD (1993) A new mixing of Hartree-Fock and local density-functional theories. J Chem Phys 98:1372-1377. https://doi. org/10.1063/1.464304

22. Reshak AH, Auluck S (2014) Electronic and optical properties of chair-like and boat-like graphene. RSC Adv 4:37411-37418. https://doi.org/10.1039/C4RA05124F

23. Reshak AH (2017) Spin-polarized second harmonic generation from the antiferromagnetic CaCoSO single crystal. Sci Rep 7:46415. https://doi.org/10.1038/srep46415

24. Reshak AH (2014) Ab initio study of TaON, an active photocatalyst under visible light irradiation. Phys Chem 16:10558-10565. https://doi.org/10.1039/C4CP00285G

25. Becke AD (1988) Density-functional exchange-energy approximation with correct as- ymptotic behavior. Phys Rev A 38:3098-3100

26. Asghari-Khiavi M, Hojati-Talemi P, Safinejad F (2009) Polarizability and first-order hyperpolarizability of cyclic imides. J Mol Struct Theochem 910:56-60

27. Wang W-Y, Kan Y-H, Wang L, Sun S-L, Qiu Y-Q (2014) Large nonlinear optical re- sponses ofdimers bearing a donor and acceptor: long, Intradimermulticenter bond-ing. J Phys Chem C 118:28746-28756

28. Zhang C-C, Xu H-L, Hu Y-Y, Sun S-L, Su Z-M (2011) Quantum chemical research on structures, linear and nonlinear optical properties of the Li@ $n$-acenes salt $(n=1,2,3$, and 4). J Phys Chem A 115:2035-2040

29. Matczak P, Wojtulewski S (2015) Performance of Møller-Plesset second-order perturba- tion theory and density functional theory in predicting the interaction between stannylenes and aromatic molecules. J Mol Model 21:41

30. Frisch MJ, Trucks GW, Schlegel HB, Scuseria GE, Robb MA, Cheeseman JR, Scalmani G, Barone V, Mennucci B, Petersson GA et al (2009) Gaussian 09, Revision A.02, Gaussian. Inc, Wallingford

31. Reshak AH (2014) $\mathrm{Fe}_{2} \mathrm{MnSi}_{\mathrm{x}} \mathrm{Ge}_{1-\mathrm{x}}$ : influence thermoelectric properties of varying the germanium content. RSC Adv 4:39565-39571. https://doi.org/10.1039/C4RA02669A

32. Veved A, Ejuh GW, Djongyang N (2019) Study of the optoelectronic and piezoelectric properties of $\mathrm{ZrO}_{2}$ doped PVDF from quantum chemistry calculations. Chin J Phys. https://doi. org/10.1016/j.cjph.2019.10.022

33. Ejuh GW, Tchangnwa Nya F, Djongyang N, Ndjaka JM (2018) Study of some properties of quinone derivatives from quantum chemical calculations. Opt Quantum Electron 50:336
34. Kabé C, Tchangnwa Nya F, Ejuh GW, Ndjaka JM (2020) Comparative study of optoelectronic, thermodynamic, linear and nonlinear optical properties of methyl phenalenyl doped to zinc and copper and their applications. J Mater Sci Mater Electron 31(10):7898-7904

35. Fankam JBF, Ejuh GW, Nya FT, Ndjaka JMB (2020) Study of electronic structure, optoelectronics, linear and nonlinear optical properties and chemical descriptors of dibromodinitrofluorescein isomers in gas phase and solvent media using $\mathrm{Ab}$ Initio and DFT methods. Chin J Phys. https://doi.org/10.1016/j. cjph.2020.05.015

36. Freude $D$ (2006) Chapter: radiation. J Spectrosc 1-21

37. Spott A, Jaron-Becker A, Becker A (2014) Ab initio and perturbative calculations of the electric susceptibility of atomic hydrogen. Phys Rev A 90:1-6

38. Yu X, Hou Y, Zhao H, Fu J, Zheng M, Zhu M (2019) The role of secondary phase in enhancing transduction coefficient of piezoelectric energy harvesting composites. J Mater Chem 7:3479. https://doi.org/10.1039/c9tc00322c

39. Olsen RB, Evans D (1983) Pyroelectric energy conversion: hysteresis loss and temperature sensitivity of a ferroelectric material. J Appl Phys 54:5941-5944. https://doi.org/10.1063/1.331769

40. Nye JF, (1961) Physical Properties of Crystals. Clarendon Press, Oxford (1957). Traduction française: Propriétés physiques des cristaux. Dunod, Paris

41. Nguyen THL, Laffont L, Capsal JF, Cottinet PJ, Lonjon A, Dantras $E$, Lacabanne $C$ (2015) Magnetoelectric properties of nickel nanowires-P(VDF-TrFE) composites. Mater Chem Phys 153:195. https://doi.org/10.1021/acs.iecr.5b02860

42. Fonkem C, Ejuh GW, Tchangnwa Nya F, Yossa Kamsi RA, Ndjaka JMB (2019) Theoretical study of optoelectronic properties of the molecule 2-cyano-3-[4-(diphenylamino)phenyl] acrylic acid. J Iran Chem Soc. https://doi.org/10.1007/s13738-019-01790-4

43. Davydyuk GE, Khyzhun OY, Reshak AH, Kamarudin H, Myronchuk GL, Danylchuk SP, Fedorchuk AO, Piskach LV, Yu Mozolyuk M, Parasyuk OV (2013) Photoelectrical properties and the electronic structure of $\mathrm{TI}(1-\mathrm{x}) \operatorname{In}(1-\mathrm{x}) \mathrm{Sn}(\mathrm{x}) \mathrm{Se} 2(\mathrm{x}=0,0.1,0.2,0.25)$ single crystalline alloys. Phys Chem Chem Phys 15:6965-6972. https://doi.org/10.1039/C3CP50836F

44. Ejuh GW, Tchangnwa Nya F, Ottou Abe MT, Jean-Baptiste FF, Ndjaka JMB (2017) Electronic structure, physico-chemical, linear and nonlinear optical properties analysis of coronene, $6 \mathrm{~B}-, 6 \mathrm{~N}-$, $3 B 3 \mathrm{~N}-$, substituted $\mathrm{C}_{24} \mathrm{H}_{12}$ using RHF, B3LYP and wB97XD methods. Opt Quantum Electron 49:382. https://doi.org/10.1007/ s11082-017-1221-2

45. Ejuh GW, Ottou MT, Tchangwa Nya F, Ndjaka JMB (2018) Prediction of electronic structure, dielectric and thermodynamical properties of flurbiprofen by density functional theory calculation. Karbala Inter J Modern Sci 4:12-20. https://doi. org/10.1016/j.kijoms.2017.10.001

46. Sarkar R, Kundu TK (2018) Density functional theory studies on PVDF/ionic liquid composite systems. J Chem Sci. https://doi. org/10.1007/s12039-0181522-4

47. Ejuh GW, Nouemo S, Tchangnwa Nya F, Ndjaka JM (2016) Modeling of the electronic, optoelectronics, photonic and thermodynamics properties of 1,4-bis(3-carboxyl-3-oxo-prop-1- enyl) benzene molecule. J Iran Chem Soc 135:2039-2048. https://doi. org/10.1007/s13738-016-0921-z

48. Jiang S, Jin L, Hou H, Zhang L (2019) Polymer-based nanocomposites with high dielectric permittivity. In: Guo JZ, Song K, Liu C (eds) Polymer-Based Multifunctional Nanocomposites and their Applications. Elsevier, Amsterdam, pp 201-243

49. Kaatz P, Donley EA, Shelton DP (1998) A comparison of molecular hyperpolarizabilities from gas and liquid phase measurements. J Chem Phys 108:849. https://doi.org/10.1063/1.475448 
50. Gümüs HP, Tamer Ö, Avci D, Tarcan E, Atalay Y (2014) Theoretical investigations on nonlinear optical and spectroscopic properties of 6-(3,3,4,4,4-pentafluoro-2-hydroxy-1-butenyl)-2,4-pyrimidinedione: An efficient NLO material. Russ J Phys Chem A 88(13):2348-2358. https://doi.org/10.1134/S00360244141300 68

51. Pegu D, Deb J, Van Alsenoy C, Sarkar U (2017) Theoretical investigation of electronic, vibrational, and nonlinear optical properties of 4-fluoro-4-hydroxybenzophenone. Spectrosc Lett 50(4):232-243. https://doi.org/10.1080/00387010.2017.13083 81

52. Li Y, Zhang Y, Qi D (2014) Nonlinear optical properties and performance optimization of the pro-aromatic chromophores for NLO materials. J Mater Sci Mater Electron. https://doi. org/10.1007/s10854-014-2298-z

53. Islam N, Chimni SS (2016) DFT investigation on nonlinear optical (NLO) properties of novel borazine derivatives. Comput Theor Chem 1086:58-66. https://doi.org/10.1016/j.compt c.2016.04.016

54. Islam N, Chimni SS (2017) Geometrical structure and nonlinear response variations of metal $\left(\mathrm{M}=\mathrm{Ni}^{2+}, \mathrm{Pd}^{2+}, \mathrm{Pt}^{2+}\right)$ octaphyrin complex derivatives: A DFT study. J Coord Chem 70(7):12211236. https://doi.org/10.1080/00958972.2017.1290799

55. Andraud C, Brotin T, Garcia F, Pelle P, Goldner B, Bigot A. Collet (1994) Theoretical and experimental investigations of the nonlinear optical properties of vanillin, polyenovanillin, and bisvanillin derivatives. J Am Chem Soc 116:2094-2102. https:// doi.org/10.1021/ja00084a055

56. Brissaud M (2007) Matériaux piézoélectriques : caractérisation, modélisation et vibration, Presses polytechniques et universitaires romandes

57. Veved A, Ejuh GW, Djongyang N (2019) Effect of HfO2 on the dielectric, optoelectronic and energy harvesting properties of PVDF. Quantum Electron, Opt. https://doi.org/10.1007/s1108 2-019-2042-2

58. Wang T, Liao Y, Wang D, Zheng Q, Liao J, Xie F, Lin D (2018) Cycling- and heating-induced evolution of piezoelectric and ferroelectric properties of CuO-doped $\mathrm{K} 0.5 \mathrm{Na} 0.5 \mathrm{NbO} 3$ ceramic. J Am Ceram Soc. https://doi.org/10.1111/jace.15931

59. Das S, Biswal AK, Parida KRNP, Roy Choudhary A (2018) Electrical and mechanical behavior of PMN-PT/CNT based polymer composite film for energy harvesting. Appl Surf Sci 428:356-363. https://doi.org/10.1016/j.apsusc.2017.09.077

60. Damjanovic D (1998) Ferroelectric, dielectric and piezoelectric properties of ferroelectric thin films and ceramics. Rep Prog Phys 61:1267-1324. https://doi.org/10.1088/0034-4885/61/9/002

Publisher's Note Springer Nature remains neutral with regard to jurisdictional claims in published maps and institutional affiliations. 